\title{
$\mathrm{NaCl}$ 및 Jasmonic Acid가 애플민트(Mentha suaveolens Ehrh.)의 생장과 생리적 반응에 미치는 영향
}

\author{
최 영 · 장매희* \\ 서울여자대학교 원예생명조경학과
}

\section{Effects of $\mathrm{NaCl}$ and Jasmonic Acid on Growth and Physiological Responses of Apple Mint(Mentha suaveolens Ehrh.)}

\author{
Young Choi and Maehee Chiang* \\ Dept. of Horticulture, Biotechnology \& Landscape Architecture, Seoul Women's Univ., Seoul 139-774, Korea
}

\begin{abstract}
This study was conducted to investigate the effects of $\mathrm{NaCl}$ and jasmonic acid(JA) on the growth and physiological responses of apple $\operatorname{mint}($ Mentha suaveolens Ehrh.). Apple mint was hydroponically grown for 3 weeks in Hoagland solution containing 0 (untreated control), $\mathrm{JA}(20 \mu \mathrm{M} \mathrm{JA}$ pretreatment), JA+NaCl $(20 \mu \mathrm{M}$ pretreatment $+50 \mathrm{mM} \mathrm{NaCl}$ treatment), and $50 \mathrm{mM} \mathrm{NaCl}$. Growth characteristics, chlorophyll, vitamin C, and proline contents, DPPH radical scavenging activity and inorganic ion contents were evaluated. As a results, there was a significant decrease in the leaf length, leaf width and shoot fresh weight of plant treated with $\mathrm{NaCl}$ or $\mathrm{JA}+\mathrm{NaCl}$ compared with control. On the other hand, the plant height and shoot fresh weight of plants treated with JA were better than control. Total chlorophyll and vitamin $\mathrm{C}$ contents were highest in the $\mathrm{JA}$ treatment. $\mathrm{Na}^{+}, \mathrm{K}^{+}$, and proline contents of plant treated wth salt $(\mathrm{NaCl}$ and $\mathrm{JA}+\mathrm{NaCl})$ were higher than those of control. Proline content of shoot was highest in JA+NaCl treatment. Also, all the salt treatments increased DPPH radical scavenging activity in all plant parts(leaf, stem, and root) compared with control, but there was no significant difference between $\mathrm{NaCl}$ and $\mathrm{JA}+\mathrm{NaCl}$ treatments. In conclusion, these results showed that moderate stress treatment such as low level salt treatment and plant growth regulator jasmonic acid(JA) would be a potential strategy to improve quality of apple mint by inducing the accumulation of secondary metabolites containing antioxidant activity and essential oil.
\end{abstract}

Key words: Antioxidant, Herb, Stress treatment

\section{I . 서론}

꿀풀과(Lamiaceae) 허브는 phenolic diterpenes, flavonoid, phenolic acid 등 항산화성뿐만 아니라 항균을 나타내는 2차 대사 산물이 비교적 풍부하여 천연 항산화제로서의 개발 가능성이 가장 큰 식물이다(Cao and Cao, 1999; Kivilomopolo and Hyotylainen, 2007). 꿀 풀과 허브 중 Mentha속 식물인 민트는 약 40여종이 널리 알려져 있는데, 특유의 향과 청량감으로 세계적으로 가장 많이 이 용되고 있는 허브로서, 정유, 향신료, 음료수, 화장품, 의약품, 치약 과 껌 등의 원료 및 첨가제로서 다양하게 사용되어 경제적 가치가

Received on January 25, 2013. Revised on April 22, 2013.

Accepted on April 24, 2013

*Corresponding author: mhchiang@swu.ac.kr
높은 식물이다(Cao and Cao, 1999). 그 중 애플민트(Mentha suaveolens Ehrh, apple mint)는 민트의 변이종으로서 향이 사과 와 박하를 섞인 듯한 순한 향이 나며 영국에서는 포프리용으로 재 배되고 있다(Park, 2003).

항산화성을 나타내는 식물의 2 차 대사산물은 원래 고온, 건조, 광, 염 등 환경 스트레스 요인을 포함한 외부자극으로부터 자신을 보호하기 위해 생성하는 물질이다. 식물 유래 천연물 항산화제로 많은 관심을 받고 있는 페놀성 화합물들 역시 photodamage로부터 자신을 보호(Close and Mcarthur, 2002)하고, 초식동물과 해충류 에 대한 방어기작으로 생성, 축적되는 성분이다(Stevenson et al., 1993). 따라서 민트의 항산화성에 영향을 주는 페놀성 화합물들 역 시 2차 대사산물로서 염 스트레스 시 방어 기작을 유도하여 함량 변 화가 될 가능성이 크다. 일반적으로, 염 스트레스는 복합적 스트레 
스를 유발시켜 식물체내 활성 산소종을 증가시키고(Greenway an d Muns, 1980), 결과적으로 생장, 광합성, 단백질 합성, 에너지나 지방질 대사 등 모든 주요한 과정에 영향을 주어 생장 억제가 일어 나지만 치사 농도나 염에 대한 생장 감소율과 내성 수준은 여러 식 물 종간에 따라 다르다(Parida and Das, 2004). Kim et al.(2010) 은 저농도의 염처리는 오히려 배추의 생장 촉진 및 생장 기간 단축 을 가져오고, 극한 가뭄 때 수확된 로즈마리 정유의 전체 생산량은 줄어들었지만 항산화 성분들은 오히려 증가하였다고 보고(Munne -Bosch et al., 1999)는, 적절한 스트레스 처리 시 허브의 품질 개선 가능성을 보여준다.

식물호르몬의 하나로 간주되는 jasmonic acid(JA) 역시 식물체 의 상처뿐만 아니라 수분 부족 등 광범위한 스트레스에 대한 signal transduction elicitor로써 방어 체계에서 결정적인 역할을 하는데 (Ohita et al., 1991), JA 역시 JA signaling pathway를 통해 terpe noids, flavonoids, alkaloids, phenylpropanoids 등의 2 차 대사사 산물을 증진시킨다고 보고되고 있다(Gundlach et al.,1992).

본 연구는 이미 항균 및 항산화성 연구가 다수 보고된 애플민트 에 저농도의 염 및 JA 처리 시 나타나는 생장 및 항산화 활성을 비교 함으로써 적절한 스트레스 처리에 의한 고부가가치 허브 식물의 재 배기술 개발 및 안전생산 가능성 검토를 위한 기초 자료로 활용하 고자 실시되었다.

\section{II. 연구방법}

\section{1. 재료 및 방법}

본 실험은 서울여자대학교 플라스틱하우스에서 7월 중순부터 8 월까지 한달간 실시하였으며, 공시재료는 허브다섯메에서 구입한 애플민트(Mentha suaveolens Ehrh.)를 이용하였다. 애플민트는 삽목번식된 것으로서 평균 초장 $15 \mathrm{~cm}$, 잎 10-15장의 균일한 개체 를 선별하여 실험에 사용하였다. 플라스틱 하우스의 온도는 $25 \pm$ $5^{\circ} \mathrm{C}$, 상대 습도는 $60-70 \%$, 평균일장 $15 \mathrm{~h}$, 맑은 날 오전 10-12시경 에 측정한 광합성유효광양자속은 $330-370 \mu \mathrm{mol} \cdot \mathrm{m}^{-2} \cdot \mathrm{s}^{-1}$ 였다. 실험 에 들어간 식물재료는 0.5 배 Hoagland 용액(Hoagland and Aron, 1950)이 공급되는 담액수경재배 시스템에서, 처리구당 8 개체를 1 반복으로, 3 반복씩 식재하였다.

Jasmonic acid(JA)는 methyl jasmonate $\left(\mathrm{C}_{13} \mathrm{H}_{20} \mathrm{O}_{3}\right.$, Sigma C o.)를 이용하였으며, JA 및 $\mathrm{NaCl}$ 처리는 0.5 배 Hoagland 용액에 서 5 일간 적응 기간을 거치고 실시하였다. 처리구는 (1) 대조구 $(0.5$ 배 Hoagland 용액 처리), (2) $20 \mu \mathrm{M} \mathrm{JA}$ 처리구(24시간 $20 \mu \mathrm{M} \mathrm{JA}$ 침지처리 후 0.5 배 Hoagland 용액으로 재배), (3) $20 \mu \mathrm{M} \mathrm{JA}$ 처리 후 $50 \mathrm{mM} \mathrm{NaCl}$ 혼용처리구 $(20 \mu \mathrm{M} \mathrm{JA} 24$ 시간 침지처리 후 $50 \mathrm{~m}$
$\mathrm{M} \mathrm{NaCl}$ 이 포함된 0.5 배 Hogland 용액처리 재배, $\mathrm{JA}+\mathrm{NaCl}$ ), (4) $50 \mathrm{mM} \mathrm{NaCl}$ 처리구 $(50 \mathrm{mM} \mathrm{NaCl}$ 이 포함된 0.5 배 Hoagland 용 액으로 재배) 등 총 4 개 처리구로 구분하였다.

\section{2. 생장 조사 및 생리적 반응 조사}

생장 특성 조사를 위해 $\mathrm{NaCl}$ 및 JA 처리 3 주후에 수확하여 초장, 엽장, 엽폭, 생체중, 건물중 등을 측정하였다. 건물중은 수확한 식물 을 $70{ }^{\circ} \mathrm{C}$ 의 건조기에서 일주일간 건조시킨 후 측정하였다. 무기성 분은 국립농업과학원 식물체 분석법(NIAST, 2000)에 준하여 실 시하였는데, 전질소는 micro-Kjeldahl법, $\mathrm{Na}^{+}, \mathrm{K}^{+}, \mathrm{Ca}^{2+}, \mathrm{Mg}^{2+}$ 는 ion chromatography(ICP-7510, Shimadzu, Japan)를 이용하였 다. 엽록소 측정은 염 및 JA 처리 2주후 제 3 엽을 채취하여 Inskeep and Bloom(1985)의 방법에 의해 측정하였다. 비타민 C 함량은 2, 6-dichlorophenolindophenol 방법(Wang et al., 1991)에 의해, D $\mathrm{PPH}$ 라디컬 소거 항산화 활성(Blois, 1958), 프롤린(proline) 함량 은 Bates et al.(1973)의 방법을 변형하여 측정하였다.

\section{3. 통계 분석}

모든 실험처리는 3 반복으로 실시하였고, 통계처리는 SPSS를 이용하였으며, 처리 평균간 유의차 검증은 분산분석을 한 후, $\mathrm{a}=0.05$ 수준에서 Duncan's multiple range test를 실시하였다.

\section{III. 결과 및 고찰}

각 처리에 따른 애플민트의 처리에 따른 애플민트의 생장은 Table 1과 같다. 초장, 엽장, 엽폭 등에서는 JA 처리구가 가장 좋았 으며, $\mathrm{JA}+\mathrm{NaCl}$ 혼용처리구 및 $\mathrm{NaCl}$ 처리구와 같은 염처리구들에 서는 대조구보다 억제되었다. 하지만, 지상부 생체중의 경우는 JA 처리구와 혼용처리구가 대조구보다 좋았는데, 두 처리구 사이에서 는 유의적 차이가 나타나지 않았다. 지하부 생체중은 지상부와는 달리 JA 처리구가 가장 높았고, 다른 세 처리구들 사이에서는 유의 적인 차이가 나타나지 않았다. 건물중 지상부는 $\mathrm{NaCl}$ 처리구가 가 장 낮았는데, 다른 처리구들 사이에서는 유의적인 차이가 나타나지 않았다. 건물중 지하부의 경우는 모든 처리구에서 유의적 차이가 나타나지 않았다.

결과적으로, 각 처리에 따른 애플민트의 생장은 $50 \mathrm{mM} \mathrm{NaCl}$ 단 독처리 시 대조구보다 생장이 억제되었고, JA 처리구에서는 초장 은 대조구보다 길어지고 엽장, 지상부의 생체중 역시 대조구보다 증가하였다. 하지만, $\mathrm{JA}+\mathrm{NaCl}$ 혼용 처리 시에는 초장과 잎의 크기 는 대조구와 비슷하였지만 지상부 생체중은 $\mathrm{NaCl}$ 단독처리보다는 증가하는 것으로 나타났다. 
Table 1. The effect of jasmonic acid and $\mathrm{NaCl}$ on the growth of apple mint grown in modified Hoagland solution for 3 weeks.

\begin{tabular}{|c|c|c|c|c|c|c|c|}
\hline \multirow{2}{*}{ Treatment } & \multirow{2}{*}{$\begin{array}{l}\text { Plant height } \\
\text { (cm) }\end{array}$} & \multirow{2}{*}{$\begin{array}{l}\text { Leaf length } \\
\quad(\mathrm{cm})\end{array}$} & \multirow{2}{*}{$\begin{array}{l}\text { Leaf width } \\
\text { (cm) }\end{array}$} & \multicolumn{2}{|c|}{ Fresh weight(g/plant) } & \multicolumn{2}{|c|}{ Dry weight $(\mathrm{g} /$ plant $)$} \\
\hline & & & & Shoot & Root & Shoot & Root \\
\hline Control & $35.63 b^{w}$ & $3.41 \mathrm{a}$ & $2.38 \mathrm{~b}$ & $5.05 \mathrm{ab}$ & $3.36 \mathrm{~b}$ & $1.46 \mathrm{a}$ & $0.40 \mathrm{a}$ \\
\hline $\mathrm{JA}^{\mathrm{z}}$ & $42.69 \mathrm{a}$ & $3.86 \mathrm{a}$ & $2.81 \mathrm{a}$ & $8.01 \mathrm{a}$ & $5.41 \mathrm{a}$ & $1.95 \mathrm{a}$ & $0.39 \mathrm{a}$ \\
\hline $\mathrm{JA}+\mathrm{NaCl}^{\mathrm{y}}$ & $32.06 \mathrm{~b}$ & $2.79 b$ & $1.95 \mathrm{c}$ & $7.95 \mathrm{a}$ & $2.85 \mathrm{~b}$ & $1.22 \mathrm{a}$ & $0.25 \mathrm{a}$ \\
\hline $\mathrm{NaCl}^{\mathrm{x}}$ & $34.63 b$ & $2.91 \mathrm{~b}$ & $1.97 \mathrm{c}$ & $3.23 b$ & $3.20 \mathrm{~b}$ & $0.95 b$ & $0.43 \mathrm{a}$ \\
\hline
\end{tabular}

${ }^{\mathrm{z}}$ Jasmonic acid treatment was a pretreatment of $20 \mu \mathrm{M}$ methyl jasmonic acid into the root part for 24 hrs before the 3-week culture.

${ }^{\mathrm{y}} 50 \mathrm{mM} \mathrm{NaCl}$ mixed with the modified Hoagland solution for 3 weeks after JA pretreatment.

${ }^{\mathrm{x}} 50 \mathrm{mM} \mathrm{NaCl}$ mixed with modified Hoagland solution for 3 weeks.

${ }^{\mathrm{w}}$ Mean separation within columns by Duncan's multiple range test at the $5 \%$ level.

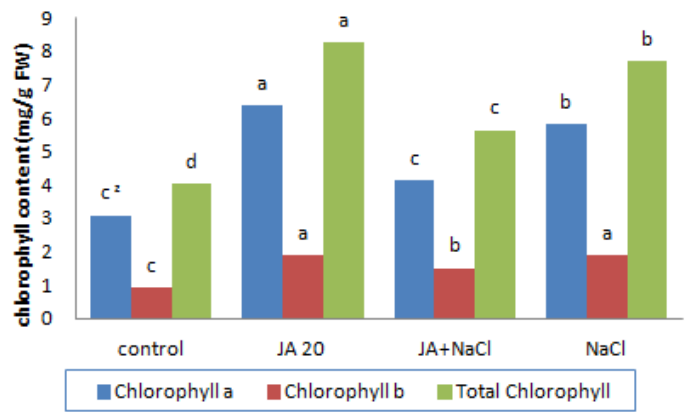

Fig. 1. The effect of jasmonic acid and $\mathrm{NaCl}$ on the chlorophyll contents of apple mint.

${ }^{z}$ Mean separation within columns by Duncan's multiple range test at the $5 \%$ level.

염에 대한 내성은 식물종에 따라서도 다른데(Parida and Das, 2004) 애플민트는 비교적 저농도의 염에도 생장이 다소 저하되어 염에 비교적 민감한 것으로 생각되었다. 배추의 경우 저농도의 염 처리는 오히려 생장이 촉진되어 생장 기간이 단축되었고(Kim et al., 2010), 콩과 식물인 Alhagi pseudoalhagi 역시 $50 \mathrm{mM} \mathrm{NaCl}$ 처리 시 무게가 증가한다고 하였다(Kurban et al., 1999). JA의 경 우, Moons et al.(1997)은 JA가 벼의 내염성과 관련이 있다고 하였 고, 건조 스트레스에 노출된 개화한 딸기에 $\mathrm{JA}(0.5-1 \mathrm{mM})$ 처리 시 딸기의 성숙 및 산출량이 증가하였다고 하였다(Yilmaz et al., 2003). 염에 다소 민감한 애플민트의 경우 단독 $\mathrm{NaCl}$ 처리보다 JA 처리 및 혼용처리 시 생장이 좋았던 것도 이와 유사한 결과였다.

$\mathrm{NaCl}$ 및 JA 처리에 따른 엽록소 함량은 모든 처리구가 대조구보 다 증가하였다(Fig. 1). 총 엽록소 함량은 JA 처리구 $>\mathrm{NaCl}$ 처리 구> 혼용처리구> 대조구 순으로 나타났는데, JA 처리구가 대조 구 엽록소 함량의 두 배로 가장 높았고, 생장이 가장 저조했던 $\mathrm{NaCl}$ 처리구 또한 대조구의 1.34배로 증가하였다(Fig. 1). 엽록소 a 함량 역시 JA 처리구가 $6.36 \mathrm{mg} \cdot \mathrm{g}^{-1} \mathrm{~F} . \mathrm{W}$.으로 대조구의 2.06 배로 증가 하였고, $\mathrm{NaCl}$ 처리구와 혼용처리구 역시 각각 대조구의 1.89 배,

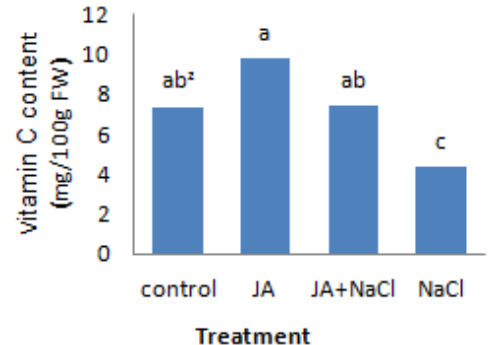

Fig. 2. The effect of the jasmonic and the $\mathrm{NaCl}$ on the vitamin $\mathrm{C}$ of apple mint. ${ }^{z}$ Mean separation within columns by Duncan's multiple range test at the $5 \%$ level.

\subsection{4 배로 증가하였다.}

엽록소 $\mathrm{b}$ 에서도 $\mathrm{JA}$ 처리구와 $\mathrm{NaCl}$ 처리구에서 모두 대조구의 2 배로 증가되었고, 혼용 처리구 역시 대조구의 1.6배 증가하였다. 일 반적으로, 잎의 엽록소는 염 조건 하에서 감소하는데(Greenway and Munns, 1980; Kim et al., 2010) 본 실험에서는 저농도의 염 및 JA 처리 시 엽록소가 증가하는 것으로 나타났다. JA 처리가 카 로티노이드 함량을 높이고(Perez et al., 1993), JA 처리 시 염에 의 한 광합성 효율이 저하되는 것을 억제한다는 보고(Tsonev et al., 1998), 염처리 시 엽록소의 일시적으로 증가한다는 보고(Kang and Shim, 1998) 등을 통해 본 실험 결과 엽록소가 증가하는 것은 일시적인 엽록소의 증진 및 JA 처리에 따른 효과 등이 복합적으로 작용한 것으로 판단된다.

각 처리에 따른 비타민 $\mathrm{C}$ 함량을 대조구와 비교하였을 때 생장이 저조하였던 $\mathrm{NaCl}$ 처리구에서만 대조구의 $66 \%$ 로 감소하였고 다 른 처리구들에서는 오히려 증가하거나 비슷한 것으로 나타났다(Fi g. 2). JA 처리구에서는 $9.74 \mathrm{mg} \cdot 100 \mathrm{~g}^{-1} \mathrm{~F}$.W.로 대조구의 1.5 배로 증가되었고, 혼용처리구 역시 대조구와 유의적 차이는 나타나지 않 았지만 대조구 $7.35 \mathrm{mg} \cdot 100 \mathrm{~g}^{-1} \mathrm{~F} . \mathrm{W}$ 에 비해 $9.74 \mathrm{mg} \cdot 100 \mathrm{~g}^{-1} \mathrm{~F} . \mathrm{W}$ 로 증가하였다. 비타민 C 함량 역시 총엽록소의 함량이 가장 높았 던 JA 처리 시가 가장 높았고, 혼용 처리 시는 $\mathrm{NaCl}$ 단독처리 시보 
Table 3. The effect of the jasmonic acid and $\mathrm{NaCl}$ on the mineral contents of applemint grown in the modified Hoagland solution for 3 weeks.

\begin{tabular}{ccccccc}
\hline \multirow{2}{*}{ Treatment } & \multirow{2}{*}{ Total N } & $\mathrm{Na}^{+}$ & $\mathrm{K}^{+}$ & $\mathrm{Ca}^{2+}$ & $\mathrm{Mg}^{2+}$ & \multirow{5}{*}{$(\% \mathrm{DW})$} \\
\cline { 3 - 6 } & & \multicolumn{5}{c}{$\mathrm{Na}^{+}$} \\
\hline Control & $1.78 \mathrm{a}^{\mathrm{w}}$ & $0.52 \mathrm{c}$ & $10.19 \mathrm{ab}$ & $6.12 \mathrm{a}$ & $2.72 \mathrm{a}$ & 19.59 \\
\hline $\mathrm{JA}^{\mathrm{z}}$ & $1.72 \mathrm{a}$ & $0.33 \mathrm{c}$ & $8.83 \mathrm{~b}$ & $5.67 \mathrm{ab}$ & $2.39 \mathrm{a}$ & 26.75 \\
\hline $\mathrm{JA}+\mathrm{NaCl}^{\mathrm{y}}$ & $1.09 \mathrm{~b}$ & $26.04 \mathrm{a}$ & $13.35 \mathrm{a}$ & $4.75 \mathrm{c}$ & $2.62 \mathrm{a}$ & 0.51 \\
\hline $\mathrm{NaCl}^{\mathrm{x}}$ & $1.57 \mathrm{a}$ & $10.39 \mathrm{~b}$ & $9.22 \mathrm{~b}$ & $4.91 \mathrm{~b}$ & $2.58 \mathrm{a}$ & 0.88 \\
\hline
\end{tabular}

${ }^{\mathrm{z}}$ Jasmonic acid treatment was a pretreatment of $20 \mu \mathrm{M}$ methyl jasmonic acid into the root part for $24 \mathrm{hrs}$ before the 3 -weeks culture.

${ }^{\mathrm{y}} 50 \mathrm{mM} \mathrm{NaCl}$ mixed with the modified Hoagland solution for 3-weeks after JA pretreatment.

${ }^{\mathrm{x}} 50 \mathrm{mM} \mathrm{NaCl}$ mixed with modified Hoagland solution for 3 weeks.

${ }^{\mathrm{w}}$ Mean separation within columns by Duncan's multiple range test at the $5 \%$ level.

Table 4. The effect of jasmonic acid and $\mathrm{NaCl}$ on the proline contents of applemint grown in the modified Hoagland solution for 3 weeks.

\begin{tabular}{ccc}
\hline \multirow{2}{*}{ Treatment } & \multicolumn{2}{c}{ Proline $\left(\mu \mathrm{mol} \cdot \mathrm{g}^{-1} \mathrm{D} . \mathrm{W}\right)$} \\
\cline { 2 - 3 } & Shoot & Root \\
\hline Control & $19.08 \mathrm{c}^{\mathrm{w}}$ & $13.78 \mathrm{~b}$ \\
$\mathrm{JA}^{\mathrm{z}}$ & $25.7 \mathrm{ab}$ & $19.08 \mathrm{a}$ \\
$\mathrm{JA}+\mathrm{NaCl}^{\mathrm{y}}$ & $27.02 \mathrm{a}$ & $13.78 \mathrm{~b}$ \\
$\mathrm{NaCl}^{\mathrm{x}}$ & $21.73 \mathrm{bc}$ & $21.73 \mathrm{a}$ \\
\hline
\end{tabular}

${ }^{\mathrm{z}}$ Jasmonic acid treatment was a pretreatment of $20 \mu \mathrm{M}$ methyl jasmonic acid into the root part for $24 \mathrm{hrs}$ before the 3-week culture.

${ }^{\mathrm{y}} 50 \mathrm{mM} \mathrm{NaCl}$ mixed with the modified Hoagland solution for 3 weeks after JA pretreatment.

${ }^{\mathrm{x}} 50 \mathrm{mM} \mathrm{NaCl}$ mixed with modified Hoagland solution for 3 weeks.

${ }^{\mathrm{w}}$ Mean separation within columns by Duncan's multiple range test at the $5 \%$ level.

다 높아졌는데 Wang(1999)도 딸기에 JA 전처리를 하면 건조 스트 레스에서 나타나는 비타민 C의 저하를 막을 수 있었다는 보고와 일 치하였다.

각 처리에 따른 애플민트의 전질소 및 이온의 함량은 Table 3 과 같다. 전질소의 경우 가장 낮은 함량을 나타낸 혼용 처리구를 제외 한 다른 처리구들에서는 유의적 차이가 나타나지 않았다. $\mathrm{Na}^{+}$함량 은 JA 처리구에서만 대조구와 유의적 차이가 없고 다른 처리구들 에서는 증가하는 것으로 나타났다. $\mathrm{NaCl}$ 처리구의 경우 대조구의 20 배 증가하였고, 혼용처리구에서는 대조구보다 50 배가 증가하여 서 혼용처리 시가 $\mathrm{NaCl}$ 단독처리 시보다 $\mathrm{Na}^{+}$의 축적이 가중됨을 알 수 있었다. 보통 $\mathrm{Na}^{+}$와 길항관계에 있는 $\mathrm{K}^{+}$의 경우 식물체내 $\mathrm{Na}^{+}$함량이 증가되면 감소되는 것이 일반적인데(Grattan and Grieve, 1999), 본 실험에서는 혼용처리 시 $\mathrm{K}^{+}$역시 증가되었던 것

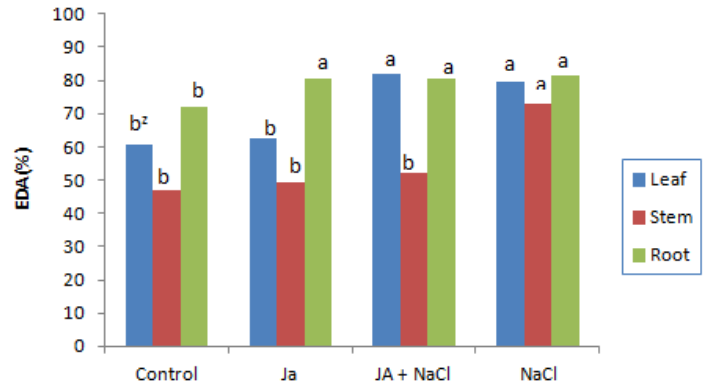

Fig. 3. The effect of JA and $\mathrm{NaCl}$ on DPPH radical scavenging activity (EDA) of apple mint.

${ }^{z}$ Mean separation within columns by Duncan's multiple range test at the $5 \%$ level.

으로 나타났다. $\mathrm{K}^{+} / \mathrm{Na}^{+}$비율은 식물체내 이온 균형 정도를 통해 단 백질 대사를 가늠할 수는 중요한 척도인데(Helal and Mengal, 1979), $\mathrm{K}^{+} / \mathrm{Na}^{+}$비율은 JA 처리구> 대조구> $\mathrm{NaCl}$ 처리구> 혼 용처리구 순으로 나타나 염에 민감한 애플민트의 경우 혼용처리 시 가 $\mathrm{NaCl}$ 단독 처리 시보다 스트레스 정도가 가중된 것으로 판단되 었다.

식물은 수분 부족, 염 스트레스 상황에 처하면 식물체내 동화산 물인 glutamic acid가 유리 프롤린으로 전환되어 삼투조절제 역할 을 하여 염류 저항성의 지표로 이용된다(Choung et al., 2003). 각 처리에 따른 애플민트의 프롤린 함량(Table 4)을 보면, 지상부에서 는 모든 처리구들에서 대조구보다 증가하였고, 그중 혼용 처리구가 가장 높았다(Chon and Park, 2003). 하지만, 지하부의 경우는 이 와는 다른 경향이 나타났는데, 지하부의 프롤린 함량은 $\mathrm{NaCl}$ 처리 구와JA 처리구가 대조구보다 증가하였지만 혼용처리 시에는 오히 려 대조구와 비슷한 수준으로 감소하였다. 이는 담배 식물에서 일 정 농도 이상의 염에서는 프롤린 함량이 오히려 감소하였다는 보고 (Lee et al, 1998)와 같이 염에 민감한 애플민트의 경우 직접적으로 염에 노출된 뿌리에서는 오히려 프롤린 함량이 낮아진 것으로 생각 되었다.

$\mathrm{DPPH}$ 라디컬 소거법을 이용하여 항산화 활성을 측정한 결과는 Fig. 3 과 같다. 잎의 항산화 활성은 혼용처리구가 $81.73 \%, \mathrm{NaCl}$ 처리구가 $79.6 \%$ 로 대조구보다증가하였고, JA 처리 $(63.95 \%)$ 시 는 대조구 $(60.65 \%)$ 와 비슷한 수치로 유의적 차이가 나타나지 않 았다. 줄기 역시 이와 비슷한 경향을 나타내었다. 뿌리의 항산화 활 성에서는 JA 처리에서도 대조구보다 항산화 활성이 증가되어, 전 반적으로 애플민트의 항산화 활성은 대조구보다 증가하는 것으로 나타났다. 꿀풀과 민트류의 항산화 능력은 주로 페놀성분에 기인하 는데(Cao and Cao, 1999), JA는 ABA와 비슷한 노화 촉진 호르몬 인 동시에 스트레스 상황에서는 방어 체계를 자극하는 신호 전달 역할로 작용한다(Raghavendra and Bhaskar Reddy, 1987). 염에 
민감한 애플민트의 경우 JA 및 저농도의 염 처리 시 나타나는 생장 반응 및 무기물, 프롤린, 항산화 활성 등을 살펴본 결과 JA 전처리 후 염처리가 항산화 활성을 증가시키면서 $\mathrm{NaCl}$ 의 생장 저하를 어 느 정도 완화시키는 것으로 나타나 적절한 스트레스 처리 시 허브 의 품질 향상 가능성을 보여주었 다. 하지만, 혼용처리 시 가중되는 $\mathrm{Na}$ 의 함량 증가 및 지상부 프롤린 함량의 증가로 미루어 염에 민감 한 애플민트의 경우 염처리에 따른 항산화 물질는 증가는 기대되나 상품 가치가 있을 정도의 안정적인 생장을 위해서는 조금 더 낮은 농도의 염처리가 적합할 것으로 판단되었고, 이에 따른 세분화된 추후 연구가 계속 진행되어야 할 것이다.

\section{$\mathrm{IV}$. 적요}

본 실험은 $\mathrm{NaCl}$ 및 JA 처리 시 애플민트(Mentha suaveolens $\mathrm{E}$ hrh.)의 생장 및 생리적 반응을 알아보고자 실시하였다. 애플민트 는 대조구, $\mathrm{JA}(20 \mu \mathrm{M} \mathrm{JA}$ 전처리), $\mathrm{JA}(20 \mu \mathrm{M} \mathrm{JA}$ 전처리 $)+50 \mathrm{mM}$ $\mathrm{NaCl}, 50 \mathrm{mM} \mathrm{NaCl}$ 처리로 0.5 배 Hoagland 용액에서 3 주간 수경 재배하였다. 생장 반응과 엽록소, 비타민 C, 프롤린, 무기물, $\mathrm{DPPH}$ 라디컬 소거 항산화 활성을 측정하였다. 그 결과, 대조구와 비교해 서 엽장, 엽폭과 지상부 생체중은 $\mathrm{NaCl}$ 와 $\mathrm{JA}+\mathrm{NaCl}$ 처리 시 유의적 으로 감소하였다. 그에 비해, JA 처리된 초장과 지상부 생체중은 무 처리된 대조구보다 높아졌다. 전체 엽록소 함량과 비타민 C는 JA 처리에서 다른 처리보다 높아졌고, 염 스트레스 처리 $(\mathrm{NaCl}$ 처리, $\mathrm{J}$ $\mathrm{A}+\mathrm{NaCl}$ 처리)된 식물의 $\mathrm{Na}^{+}, \mathrm{K}^{+}$, 프롤린 함량은 대조구보다 증가 되었다. 지상부 프롤린의 함량은 $\mathrm{JA}+\mathrm{NaCl}$ 혼용처리구가 다른 처 리구보다 높았다. 또한, 모든 염처리구에서 잎, 줄기, 뿌리의 모든 식물 부위의 항산화 활성이 무처리 대조구보다 증가하였다. 하지 만, 모든 식물의 DPPH 라디컬 소거활성은 나타나지 않았다. 결론 적으로, 이러한 결과들은 낮은 염 스트레스나 JA 처리 같은 적절한 스트레스 처리가 항산화 활성과 정유를 포함하는 이차대사물질의 축적을 유도함으로써 애플민트의 품질을 향상시킬 잠재적인 가능 성을 보여준다

\section{V. 인용문헌}

Bates, L.S., R.P. Waldren, and J.D. Tearen. 1973. Rapid determination of free proline for water-stress studies. J. Plant Soil 39:205207.

Blios, M.S. 1958. Antioxidant determination by the stable free radical. Nature 26:1198-1204.

Cao, Y.H. and R.H. Cao. 1999. Angiogenesis inhibited by drinking tea. Nature 398(6726):381-384.

Chon, S.U. and J.H. Park. 2003. Parameters on physiological responses of soybean(Glycine max merr.) to salinity. Kor. J. Environ. Agri. 22(3):185-191.

Choung, J.I., K.Y. Kim, D.H. Choi, M.K. Oh, S.Y. Lee, and D.J. Lee. 2003. Growth responses and proline accumulation by salt treatment in rice cultivars. Kor. J. Intl. Agri. 15(4):288-293.

Close, D.C. and C. Mcarthur. 2002. Rethinking the role of many plant phenolics-protection from photodamage not herbivores? Oikos 99:166-172.

Grattan, S.R. and C.M. Grieve. 1999. Salinity-mineral nutrient relations in horticultural crops. Scientia Hort. 78:125-157.

Greenway, H. and R. Munns. 1980. Mechanisms of salt tolerance in nonhalophytes. Ann. Rev. Plant Physiol. 31:149-190.

Gundulach, H., M.J. Muller, T.M. Kutchan, and M.H. Zenk. 1992. Jasmonic acid is a signal transducer in elicitor- induced plant cell cultures. Proc. Natl. Acad. Sci. 89:2389-2393.

Helal, H.M. and K. Mengal. 1979. Nitrogen metabolism of young barley plants as affected by $\mathrm{NaCl}$-salinity and potassium. J. Plant Soil 51:457-462.

Hoagland, R.D. and D.I. Aron. 1950. The water culture for growing plants without soil. Cir. 347. California Agr. Exp. Sta.

Inskeep, W.P. and P.R. Bloom. 1985. Extinction coefficients of chlorophyll concentration $\mathrm{a}$ and $\mathrm{b}$ in $\mathrm{N}, \mathrm{N}$-dimethylformamide and 80\% acetone. J. Plant Physiol. 77:483-485.

Kang, B.H. and S.I. Shim. 1998. Screening of saline tolerant plants and development of biological monitoring technique for saline stress. Kor. J. Enviro. Agri. 17(1):26-33.

Kim, J.S., I.S. Shim, and M.K. Kim. 2010. Physiological responses of Chinese cabbage to salt stress. Kor. J. Sci. Technol. 28(3): 343-352.

Kivilomopolo, M. and T. Hyotylainen. 2007. Comprehensive two-mension liquid chromatography in analysis of Lamiaceae herbs: Characterization and quantification of antioxidant phenolic acids. J. Chromatography 1145:155-164.

Kurban, H., H. Sneoka, K. Nehira, R. Adilla, G.S. Premachandra, and K. Fujita. 1999. Effects of salinity on growth, photosynthesis and mineral composition in Leguminous plant Alhagi pseudoalhagi(Bieb.). Soil. Sci. Plant Nutr. 45:851-862.

Lee, S.G., J.S. Shin, Y.S. Seok, and G.K. Bae. 1998. Effects of salt stress on photosynthesis, free proline content and ion content on tobacco. Kor. J. Eiviron. Agri. 17(3):215-219.

Moons, A., E. Prisen, G. Bauw, and M. Van Montagu. 1997. Antagonistic effects of abscisic acid and jasmonates on salt stressinducible transcripts in rice roots. Plant Cell 9:2243- 2259.

Munne-Bosch, S., K. Schwarz, and L. Alegre. 1999. Enhanced formation of a-tocopherol and highly oxidized abietane diterpenes in water-stressed rosemary plants. Plant Physiol. 121:1047-1052.

National Institute of Agricultural Science and Tecnology(NIAST). 2000. Analysis method of soil and plant. NIAST, Suwon, Korea.

Ohita H., K. Shidae, Y.L. Peng, I. Furusawa, S. Aibra, and Y. Morita. 1991. A lipoxygenase pathway is activated in rice after infection with the rice blast fungus Magnaporthe grisea. J. Plant Physiol. 9:94-98. 
Parida, A.K. and A.B. Das. 2004. Effects of $\mathrm{NaCl}$ stress on nitrogen and phosphorus metabolism in a true mangrove Bruguiera parviflora grown under hydroponic culture. J. Plant Physiol. 161:921-928.

Park, K.W. 2003. Herb and aromatheraphy. Seoul:Sunjinmunhwasa. Perez, A.G., C. Sanz, D.G. Richardson, and J.M. Olias. 1993. Methyl jasmonate vapor promotes $\beta$-carotene synthesis and chlorophyll degradation in Golden Delicious apple peel. J. Plant Growth Regulat. 12:163-167.

Raghavendra, A.S. and K. Bhaskar Reddy. 1987. Action of proline on stomata differs from that of abscisic acid, G-substraces, or methyl jasmonate. J. Plant Physiol. 83:732-734.

Stevenson, P.C., J.C. Anderson., W.M. Blaney, and M.. J.S. Developmental inhibition of Spodoptera litura(Fab.) larvae by a novel caffeoylquinic acid from the wild groundnut, Aracis paraquariensis., J. Chem. Ecol. 19:2917-2933.

Tsonev, T.D., G.N. Lazova, Z.G. Stoinova, and L.P. Popova. 1998. A possible role for jasmonic acid in adaptation of barley seeding to salinity stress. J. Plant Growth Regul. 17:153-159.

Wang, C.Y. 1999. Methyl jasmonate reduces water stress in strawberry. J. Plant Growth Regul. 18:127-134.

Wang, S.Y., H.J. Jiao, and M. Faust. 1991. Changes in ascorbate, glutathione, and related enzyme activities during thidiazuron induced bud break of apple. Physiol. Plant. 82:231-236.

Yilmaz, H., K. Yildiz, and F. Muradoglu. 2003. Effect of jasmonic acid on Yield and quality of two strawberry cultivars. J. Amer. Pomol. Soc. 57:32-35. 